\title{
LOS DOS AMANTES DEL CIELO DE CALDERÓN: FUENTES Y NOVEDADES EN LA LEYENDA DE LOS SANTOS CRISANTOY DARÍA
}

\author{
María José Tobar Quintanar \\ CPI Camiño de Santiago \\ Departamento de Lengua y Literatura castellana \\ Pedrouzo, 15821 O Pino (A Coruña) \\ maria.jose.tobar@edu.xunta.es
}

Este trabajo persigue básicamente dos objetivos: 1) determinar la fuente más probable de Calderón a la hora de escribir la comedia de santos Los dos amantes del cielo, y 2) describir los principales cambios operados por don Pedro para convertir la leyenda de los santos Crisanto y Daría en una pieza teatral. Sin embargo, antes de abordar esta tarea conviene ofrecer algunos datos sobre la obra calderoniana en cuestión y sobre la materia hagiográfica que dramatiza.

Se desconoce la fecha de composición de Los dos amantes del cielo. Según Hilborn esta comedia fue escrita en torno a $1636^{1}$. Para Cruickshank «podría datar de 1637-1638»; pero, ante la falta de datos inequívocos al respecto, este investigador reconoce que "podría pertenecer a casi cualquier periodo de la carrera de don Pedro» ${ }^{2}$. En el Acta sanctorum del 25 de octubre se considera posterior a la ordenación sacerdotal de Calderón (1651) ${ }^{3}$. Apareció publicada en la Verdadera quinta parte de comedias del dramaturgo (Madrid, 1682).

${ }^{1}$ Hilborn, 1938, pp. 21, 32, 34 .

${ }^{2}$ Cruickshank, 2011, pp. 335 y 333, respectivamente.

3 Acta Sanctorum, Octobris [día 25 de octubre], p. 444b: «Opus [Los dos amantes del cielo] hoc scriptum putem ab auctore cum jam presbyter esset». 
Se ignora también si existió alguna circunstancia (devoción personal, festividad religiosa o encargo particular) que motivó la redacción de esta obra, la única dedicada en el teatro del Siglo de Oro español a los santos Crisanto y Daría ${ }^{4}$. En cualquier caso, la conversión y la pasión de estos mártires presentan episodios con un gran potencial dramático que don Pedro supo aprovechar para su producción hagiográfica.

De manera resumida, la leyenda de esos santos es la siguiente. Crisanto, hijo del senador romano Polemio, originario de Alejandría, es un joven con inquietudes intelectuales. La lectura casual de los Evangelios despierta curiosidad en él y ese afán por entender su significado le conduce a Carpoforo, un cristiano muy docto en las divinas escrituras. Sus enseñanzas logran la conversión del protagonista, quien empieza a predicar públicamente su fe. Enterado de ello, su padre, enojado, ordena encarcelarlo hasta que renuncie a su nuevo credo. Ante la firmeza de Crisanto, un amigo aconseja a Polemio que lo tiente carnalmente con varias esclavas hermosas. Con ayuda divina el joven resiste y las mujeres caen en un sueño profundo que les impide conquistarlo. Polemio recurre entonces a una virgen llamada Daría — consagrada a la diosa Minerva o a Vesta, según las distintas versiones del relato-, bella y erudita, para que con sus razonamientos consiga hacerle volver al paganismo y, enamorado, se case con ella.Tras un intenso intercambio de argumentos, Crisanto convierte al cristianismo a Daría. Ambos, guardando su virginidad, fingen ser esposos para obtener la libertad del joven. Conocida por las autoridades la divulgación de la doctrina cristiana por parte de la pareja, son prendidos y, ante su negativa a adorar a los dioses gentiles, condenados a padecer varios tormentos. Estos, sin embargo, nunca se llegan a ejecutar gracias a la intervención del cielo. Tales prodigios motivan la conversión del tribuno Claudio, su familia y sus soldados, quienes sufren martirio por ello. El propio emperador Numeriano decide entonces su castigo: Crisanto es enviado a la cárcel y Daría, a un prostíbulo. En este lugar se manifiesta de nuevo el auxilio divino: un león aparece para impedir la violación de la virgen. Los nuevos suplicios que se determinan para ambos fracasan una vez más. Finalmente, Crisanto y Daría son enterrados vivos en una hoya y sepultados bajo tierra y piedras.

Los hechos narrados se fechan en el siglo III, aunque - como suele ser habitual en este tipo de textos- no faltan discrepancias cronológicas en el propio relato: Crisanto y Daría fueron martirizados en tiempos del

\footnotetext{
${ }^{4}$ Ver Menéndez Peláez, 2004, pp. 747, 799.
} 
emperador Numeriano (ca. 283-284), pero su pasión fue redactada por los presbíteros Varino y Armenio por orden del papa Esteban (muerto en el año 257) ${ }^{5}$. La Iglesia romana celebra su festividad el 25 de octubre.

Para dilucidar las fuentes de Los dos amantes del cielo es necesario un estudio previo de la transmisión de la leyenda que esta comedia lleva a escena. A ello se dedica el primer apartado de este trabajo.

\section{LA TRADICIÓN hagiográfica SOBRE los SANTOS CRISANTO y DARÍA}

El testimonio más antiguo dedicado a la memoria de estos mártires es un epigrama del papa san Dámaso en el siglo IV. En el vi, Gregorio de Tours los incluyó - aunque sin referir su vida ni su pasión- en el libro De gloria martyrum (cap. 38) ${ }^{6}$. Entre los siglos V-VII podría datarse el relato individual de su martirio: la Passio Chrysanthi et Dariae, que se transmitió de forma manuscrita durante la Edad Media ${ }^{7}$. En el s. VII san Aldhelmo, abad de Malmesbury y obispo de Sherborne, dedicó un carmen a estos santos en su tratado en alabanza de la virginidad, De laude virginitatis. En esta versión de la historia faltan algunos elementos importantes: no se mencionan los nombres ni del padre de Crisanto ni del emperador que lo condena y carece del personaje de Carpoforo ${ }^{8}$.

En el siglo Ix la historia aparece recogida en varios martirologios. En los de Rabano Mauro y Usuardo, así como en el Martirologio romano, solo se registran de forma muy breve los datos básicos de la pasión final ${ }^{9}$. En el de Adón, arzobispo de Viena que remodeló los martirologios

${ }^{5}$ El Acta de estos santos (pp. 444b-445a) y Delehaye (1998, p. 41,n. 19) señalan esta incongruencia. Alonso de Villegas la resuelve de esta manera en su Flos sanctorum (1672, p. 502b): «[...] fue su muerte [de Crisanto y Daría] a cuatro [sic], año de 280, imperando Numeriano. Los notarios que escribieron esta vida dicen que fue por mandado del Papa Estéfano, y porque murió veinticuatro años antes, hase de entender que los señaló el Pontífice (como era costumbre en Roma) para que tuviesen cargo de escribir los martirios que padecían los cristianos por Dios». (Modernizo el texto de las citas siempre que, como en este caso, sea necesario).

${ }^{6}$ Ver Acta Sanctorum, Octobris [día 25 de octubre], p. 439a (para los versos del papa san Dámaso), pp. 439b-440a (para el texto de Gregorio de Tours).

${ }^{7}$ Ver Bibliotheca Hagiographica Latina, vol. 1, p. 269 (ref. 1787) y Maggioni, 1998, vol. 1, p. LVIII, donde se especifica que Bonino Mombricio, humanista milanés del s. XV, recogió esa pasión en su Sanctuarium seu Vitae sanctorum.

${ }^{8}$ Ver Acta Sanctorum, Octobris [día 25 de octubre], pp. 488a-489b (PL 89, cols. 258260).

${ }^{9}$ Mauro, Martyrologium, p. 107; Usuardo, Martyrologe, p. 351; Martirologium secundum morem Romanae curie, bajo el epígrafe "De mense octobris. Octavo kalendas novembris luna», [p. 128]. 
de la tradición griega, la leyenda se desarrolla de manera más extensa y detallada, registrándose la nómina de personajes más completa hasta la fecha (en la que se halla Carpoforo). Por lo demás, la omisión en este testimonio del episodio de la tentación de Crisanto tal vez se deba a una autocensura del propio Adón ${ }^{10}$.

La transmisión del relato en su vertiente oriental no continuó en las Vidas de santos de Simeón Metafrastes, del siglo X, sino a través de diversos manuscritos griegos, como los denominados Coisliniano (s. XI) y Colbertino (s. $\mathrm{XII}$ ), en los que figura el maestro cristiano Carpoforo y se considera a Daría una virgen consagrada a la diosa Minerva (virgo Minervae) ${ }^{11}$.

En cuanto a la tradición occidental, la difusión manuscrita en latín de la pasión de Crisanto y Daría culminó en el s. XIII (ca. 1260) con su inclusión en el famoso legendario de Jacobo de Vorágine (o da Varazze), la Legenda aurea. Algunos de los principales rasgos de su texto son: la omisión del personaje de Carpoforo, de los familiares que asesoran a Polemio y de la descriptio inicial de Crisanto; la referencia numérica concreta a cinco jóvenes que pretenden seducir al mártir; la vinculación de Daría con el culto a la diosa romana Vesta; la abbreviatio de la argumentación que logra la cristianización de aquella y la supresión del proceso de conversión del tribuno Claudio ${ }^{12}$.

De la obra deVarazze arrancan dos traducciones independientes al castellano, las denominadas Compilación A (s. Xv) y Compilación B (ss. XIV-Xv). De los siete manuscritos que transmiten la primera, dos acogen nuestra leyenda; de los ocho que transmiten la segunda, $\operatorname{tres}^{13}$. Los materiales de la Compilación $A$ dieron lugar al texto impreso que hoy conocemos como Flos Sanctorum renacentista, con sucesivas ediciones entre 1516 y $1580^{14}$. Para la redacción de la historia de Crisanto y Daría que ahí figura se consultaron más fuentes que la Legenda aurea, pues cuenta con el perso-

${ }^{10}$ Ver Acta Sanctorum, Octobris [día 25 de octubre], pp. 443b-444b.

${ }^{11}$ Ver Acta Sanctorum, Octobris [día 25 de octubre], pp. 442b, 443b.

${ }^{12}$ Vorágine, Legenda aurea, vol. 2, pp. 1071-1072.

${ }^{13}$ Se trata, para la Compilación $A$, de los mss. Esc h-II-18 y BNE 12689; y, para la Compilación B, de los mss. Esc h-I-14, Esc k-II-12 y L.G. 419 (sección 2a). Ver Aragüés Aldaz, 2004, pp. 527-533 y 540-546.

${ }^{14}$ Manejo la edición (revisada por Gonzalo Millán a partir de la de Pedro de la Vega) que lleva por título Flos sanctorum: el más copioso que hasta agora ha sido impreso (Sevilla, Juan Gutiérrez, 1569). Para la historia de los Flores sanctorum medievales y renacentistas en las letras castellanas, ver Aragüés Aldaz, 2000, 2004, 2005, 2012, 2014, y González Lopo, 2004. 
naje de Carpoforo, con una detallada caracterización del protagonista y de su padre, y con la alusión a los parientes que advierten a este último. A partir del pasaje en que Crisanto es tentado por cinco doncellas, el relato sigue de cerca la versión de Vorágine. De la Compilación B deriva el impreso de la Leyenda de los santos (que vulgarmente Flos Santorum llaman) (ca. 1490) ${ }^{15}$. Este, aunque sigue el texto de la Legenda aurea, omite algunos datos (como el nombre del emperador Numeriano o la diosa pagana relacionada con Daría) y presenta alguna lectura errónea (por ejemplo, Polemio de Alejandría es "Apolo de Apolonia»).

Los santorales renacentistas postridentinos, animados por un espíritu de mayor rigor hagiográfico, se inician con las Vitarum sanctorum priscorum patrum (1551-1560) de Luis Lipomano, obispo de Bérgamo y Verona. Puesto que este autor traduce del griego al latín las leyendas compiladas por Metafrastes, no registra la de Crisanto y Daría ${ }^{16}$. Sí aparece, en cambio, en el tomo 5 del De probatis sanctorum historiis (1570-1575) de Lorenzo Surio, continuador de la labor de Lipomano ${ }^{17}$. La dependencia de su texto con la tradición oriental es clara: no falta el personaje de Carpoforo (antes, al contario, su papel está muy desarrollado) y Minerva es la diosa a cuyo culto se dedica Daría. Se trata de la versión más extensa de la leyenda: abunda en los rasgos que caracterizan a Polemio y Crisanto, en los argumentos que lograron la conversión de los mártires y en los tormentos decretados para ellos. Además, se precisa que fue un pariente de Polemio quien le aconsejó recurrir a varias siervas suyas - cuyo número concreto no se especifica - para apartar a Crisanto de la fe cristiana.

${ }^{15}$ Manejo la transcripción moderna del ejemplar existente en el Archivo Histórico de Loyola, único conocido de la edición hecha en Sevilla, en 1520-1521, por el impresor salmantino Juan de Varela. Para Crisanto y Daría, ver pp. 46-47.

${ }^{16} \mathrm{He}$ consultado el t. 6 de esta obra - el correspondiente a los santos de los meses de mayo a octubre- (Roma, 1558). Tampoco figuran Crisanto y Daría en su libro De vitis sanctorum, pars prima (Lovanii, 1571).

17 Surio comete, en este caso, el error de señalar a Metafrastes como su fuente: «Sanctorum Chrysanthi et Dariae historia, scripta a Varino \& Armenio. Habetur in Metafraste, consentiuntque antiqui ms. codices latini», p. 948. Siguiendo su testimonio, Villegas (Flos sanctorum, p. 498b) y Ribadeneyra (Flos sanctorum, p. 789b) reproducen este yerro. Lo que resulta indudable es que el cartujo alemán conoció la leyenda, al menos, a través de la versión de Adón, pues editó — junto con Lipomano- su Martirologio (ver Bibliotheca Hagiographica Latina, vol. 1, p. 270). Para la historia de los santos Crisanto y Daría, ver pp. 948-955 del tomo citado de la obra de Surio. 
Los legendarios castellanos que se basan en la obra de Surio, y no en la Legenda aurea de Vorágine, son los Flos sanctorum de Alonso de Villegas (1 $1^{\mathrm{a}}$ ed., 1578) y Pedro de Ribadeneyra (1 ${ }^{\mathrm{a}}$ ed., 1599), y La hagiografía y vidas de los santos del Nuevo Testamento. Primera y Segunda Parte de Juan Basilio Sanctoro $\left(1^{\mathrm{a}} \text { ed., 1580 }\right)^{18}$. Villegas y Ribadeneyra declaran abiertamente esta fuente, pero no sucede lo mismo con Sanctoro, quien remite al Martyrologio de Adón y al libro De gloria martyrum de Gregorio de Tours. La versión que reproduce más fielmente el texto latino de Surio es la de Sanctoro; la de Ribadeneyra es la que más se aleja — por omisión de datos - de él. Demostraré lo dicho con dos pasajes de nuestra leyenda: el primero, referido a la tentación de José por la mujer de Putifar (a la que Crisanto alude cuando sufre la suya propia); el segundo, un fragmento del proceso de conversión del tribuno Claudio (tras haber presenciado varios prodigios favorables a Crisanto).

\section{SURIO}

Sic \& beatus servus tuus Ioseph meretricis, tanquam immanis ferae, manus effugit auxilio tuo. Quem cum pater Iacob deploraret: Improba, dicebat, fera devoravit filium meum: neque ullam volebat admittere consolationem. Vere enim nihil eum celabas. Sed tamen cum dicerent filii eius: Vide, utrum sit haec tunica filii tui: non indicasti ei: sed rem abscondisti, ut paternis lachrymis subvenires. Uxor enim Phutiphar, tanquam fera crudelis eum invaserat \& unguibus eum, quasi leona quaedam dilaniabat: $\mathcal{E}$, quod gravissimum est, insidias tendebat, ut solus cum sola dormiret.

\section{VILLEGAS}

Así tu bendito siervo José, cuando Jacob su padre le lloraba y decía que una terrible bestia se le había tragado, no iba fuera de camino: porque la mujer de Putifar le había acometido, y con uñas como leona cruel, pretendiendo despedazarle: y daba trazas como él solo con ella sola, te ofendiesen. Mas, Señor, no estaba solo José, pues tú le defendiste con tu gracia y libraste con tu poderosa mano. Sabido después por su viejo padre [...] (p. 499b)

\section{SANCTORO}

Desta manera tu bienaventurado siervo José con tu favor se escapó de las manos de la cruel fiera que era la mujer de Putifar, que como leona lo quería despedazar tratando que solo con ella sola durmiese. Mas no estaba solo, pues con tu favor lo defendías. ¿Qué otra cosa era la fiera que su padre lloraba que lo había tragado, sino esta tentación carnal, con la cual el demonio y la mujer lo combatían? La carne y sangre de la mocedad hervía, el hincar de los ojos de ella lo convidaba, allegábase la potencia de su ama y la persuasión para la torpeza, y el ornato de la mujer sembrado de oro y piedras preciosas le anublaban los ojos. [...] (p. 252r)

\section{RIBADENEYRA}

[Ø] (p. 787b)

${ }^{18}$ Para el martirio de Crisanto y Daría, verVillegas, Flos sanctorum, 1672, pp. 498b$502 \mathrm{~b}$; Sanctoro, Segunda parte de la hagiografía y vidas de los santos del Nuevo Testamento, 1580, pp. 251v-254v; y Ribadeneyra, Flos sanctorum, 1610, pp. 787a-789b. 
Sed solus non erat, quoniam ope tua eum protegebas. Idcirco enim permisisti, ut eum ex profundo corde lugeret pater, ut iusti precibus adolescentulus adiuvaretur. Quid enim aliud erat fera, nisi libido, per quam ipse diabolus $\mathcal{E}$ foemina eum oppugnabant? Caro \& sanguis adolescentiae fervebat. Oculorum obtutus invitabant. Accedebat here potentia, \& turpitudinem adhortatio. Ornatus muliebris, auro margaritisque distinctus, atque omni lapide precioso, oculorum aciem perstringebat. [...] (p. 950r)

Et, Quaenam, inquit, Rogole que le declaest vis ista praestigia- rase qué arte mágica rum, quibus haec effi- era la suya, con que cis? Omnes ego magos, así se libraba de los incantatoresque domui: tormentos, que obenec ullam tantam ma- deciese al mandato de giae potentiam inveni. los emperadores, en Omnes a me victi sunt: lo cual mostraría que omnis eorum malitia era sabio y avisado, meae cessit voluntati. sin poner nota en su Caeterum cum te vi- linaje y enojar a los deam virum praeclarum \& sapientem, non aliud abs te requiro, nisi ut audax deferas Christianorum institutum, quo tumultus atque seditio in populo Romano excitatur, teque genere tuo dignum praebeas, E omnipotentibus diis debita facias sacrificia. (p. 953)
[Y díjole Claudio] [Ø] (p. 788b) ¿Qué fuerza es esta de tus hechicerías que tales cosas hace? Yo he castigado y domado todos los magos y encantadores desta tierra, mas nunca hallé tanta potencia de la arte mágica. Todos fueron por mí vencidos y quedaron sujetos a mi voluntad. En lo demás, porque te veo ser varón clarísimo y sabio, no quiero de ti otra cosa sino que dejes la ley de los cristianos, por la cual se levantan tantos tumultos y escándalos en el pueblo romano, y que te muestres digno de tu linaje y hagas debidos sacrificios a los omnipotentes dioses. (p. 253v)

El estudio de la filiación de Los dos amantes del cielo con la variante oriental de la leyenda recogida por Surio y el establecimiento de la probable fuente de Calderón se abordan en el siguiente epígrafe.

\section{LAS FUENTES DE LOS DOS AMANTES DEL CIELO}

En su trabajo sobre las hagiografias individuales publicadas en español de 1480 a 1700, Simón Díaz no registra ninguna que transmita 
la leyenda de Crisanto y Daría ${ }^{19}$. Ello nos encamina — con la necesaria prudencia en el acercamiento a las fuentes de una obra, afectadas por un estado de provisionalidad permanente- hacia los santorales colectivos mencionados líneas atrás.

Varios datos relacionan la comedia de Calderón con el texto de Surio (y los derivados de este) de modo indudable. Quizás el más evidente sea la existencia del personaje de Carpoforo, presentado como un docto maestro que habita en una cueva para huir de la persecución a la que es sometido como cristiano.

SURIO

Villegas

SANCTORO

RIBADENEYRA

Calderón

«virum quendam Christianum, nomine Carpophorum, divinarum scripturarum peritissimum: qui propter impiam persecutionem, in montibus spelunca quadam habitaret, qui sane locus perquam paucis notus esset» (p. 949)

«un gran varón cristiano, llamado Carpoforo, bastantemente enseñado en las divinas letras, que estaba encerrado en una cueva por temor de la persecución que contra los cristianos andaba» (p. 499a)

«un varón cristiano y presbítero llamado Carpoforo, doctísimo en las divinas escripturas, el cual por la desapiadada persecución habitaba en los montes en una cueva por pocos sabida» (p. 252r)

«un cristiano llamado Carpoforo, bien enseñado en las divinas letras, por temor de la persecución, estaba escondido en una cueva» (p. 787b)

«[...] Carpoforo, / que en Roma / fue el más celebrado maestro / en todas ciencias y hoy, / del Emperador huyendo / por sospechas de cristiano, / en los ásperos desiertos / habita, racional fiera» (p. 239); «de ese monte en lo desierto / la cueva de Carpoforo» ${ }^{\star}$ (p. 244)

* Cuando Carpoforo finge ser un médico dispuesto a 'curar' a Crisanto, declara su procedencia griega: «Soy de Atenas» (p. 291). Se trata de un indicio más del seguimiento por parte de Calderón de la vertiente oriental de la leyenda, traducida al latín por Surio.

También la presentación de Polemio y Crisanto en la pieza calderoniana revela su dependencia de la versión del cartujo alemán. El primero

\footnotetext{
${ }^{19}$ Ver Simón Díaz, 1977.
} 
es un senador principal, procedente de Alejandría, que goza de gran honra por el favor del emperador Numeriano. El segundo, su hijo, es un joven ingenioso que se aplica intensamente al estudio.

SURIO

VILLEGAs

SANCTORO «Fue en Alejandría un varón ilustre y principal de la or-
den de los senadores llamado Polemio, el cual vino a Roma,
con un hijo que tenía y se decía Crisanto, donde fue por
todo el Senado amigablemente recebido, y favorecido del
emperador Numeriano con grandes honras, y alcanzó silla
en el mesmo Senado romano» (p. 251v)
b) «Teniendo, pues, Polemio deseo que su hijo fuese insti-
tuido en las ciencias, púsolo en los estudios de la filosofía, y
como él fuese ingenioso y aparejado para deprender, alcan-
zó tanta prudencia como esta historia lo mostrará» (p. 251v)
a) «Fue san Crisanto de la ciudad de Alejandría, hijo de
un caballero ilustre del Senatorio, llamado Polemio, el cual
había venido a vivir a Roma con toda su casa y familia, y
había sido recebido amigablemente del Senado y muy hon-
rado del emperador Numeriano» (p. 787a)
b) «su hijo Crisanto, que era de delicado y alto ingenio, se
ejercitase en los estudios de todas buenas letras» (p. 787b)

SANCTORO «Fue en Alejandría un varón ilustre y principal de la or-
den de los senadores llamado Polemio, el cual vino a Roma,
con un hijo que tenía y se decía Crisanto, donde fue por
todo el Senado amigablemente recebido, y favorecido del
emperador Numeriano con grandes honras, y alcanzó silla
en el mesmo Senado romano» (p. 251v)
b) «Teniendo, pues, Polemio deseo que su hijo fuese insti-
tuido en las ciencias, púsolo en los estudios de la filosofia, y
como él fuese ingenioso y aparejado para deprender, alcan-
zó tanta prudencia como esta historia lo mostrará» (p. 251v)
a) «Fue san Crisanto de la ciudad de Alejandría, hijo de
un caballero ilustre del Senatorio, llamado Polemio, el cual
había venido a vivir a Roma con toda su casa y familia, y
había sido recebido amigablemente del Senado y muy hon-
rado del emperador Numeriano» (p. 787a)
b) «su hijo Crisanto, que era de delicado y alto ingenio, se
ejercitase en los estudios de todas buenas letras» (p. 787b)

a) «Vir quidam Alexandrinus, in civitate sua illustris ac princeps, ordinisque Senatorii, nomine Polemius, Romam cum filio suo Chrysantho concessit. Qui a Senatu Romano amice susceptus, maximisque honoribus ab Imperatore Numeriano auctus, sellam in Senatu Romanorum obtinuit» (p. 949)

b) «Hic filium unicum Chrysanthum, quem disciplinis omnibus imbuendum curaverat, Philosophorum studio tradidit. Erat autem adolescens ingeniosus \& ad discendum aptissimus» (p. 949)

a) «Había en la ciudad de Alejandría un ilustre ciudadano, del orden senatorio, llamado Polemio. Tenía un hijo, cuyo nombre era Crisanto, y con él y su hacienda, casa y familia pasó a vivir a Roma. Fue recibido amigablemente del Senado, y del emperador Numeriano muy honrado. Mandole dar asiento entre los senadores» (p. 498b)

b) «su hijo Crisanto, de cuyo alto entendimiento y delicado juicio tenía grande experiencia, se ejercitase en los estudios y letras de humanidad» (pp. 498b-499a) 
Calderón a) «[Polemio] [...] tengo / hoy, por el gran Numeriano, / generoso césar nuestro, / el gran gobierno de Roma / y del mundo, pues gobierno, / primero senador, todas / las provincias de su imperio? / ¿De Alejandría, mi patria, / a donde los timbres tengo / de mi sangre, no me trujo / para repartir el peso / de su corona conmigo» (p. 241)

b) «[CRisanto $[\ldots]$ yo, que ha tantos / años que estudio y que leo / divinas y humanas letras» (p. 236); «[POLEmio] Bien, de mirarte aplicado / hoy a los libros, me huelgo; / pero no la aplicación / ha de ser con tanto estremo / que te enajene de todo» (p. 241); "[Claudio] Un joven, a quien dotó / de tantas partes el cielo, / como son nobleza, gala, / hacienda, valor y ingenio, / ¿[...] / la edad mejor de su vida / solo ha de gastar leyendo?» (p. 241)

Aunque Calderón introduce a Daría como sacerdotisa de la diosa romana Diana — asociada obviamente con la virginidad de la doncella-, no falta en la comedia una alusión a Minerva, la deidad griega citada por Surio:

SURIO

Villegas

SANCTORO

RiBADENEYRA

Calderón
«Est inter virgines Minervae una [...]» (p. 950)

«Entre las doncellas de Minerva, dice el amigo, está una $[\ldots] »($ p. 500a)

«Entre las vírgines de Minerva está una llamada Daría $[\ldots] »($ p. 252v)

«Halló entre las vírgenes de Minerva una que se llamaba Daría» (p. 788a)

«[Cintia] En tanto que las hermosas / discípulas de Minerva / [...] / vuelven en fragantes rosas / bajando a estas selvas bellas» (p. 247)

Otros elementos de la historia permiten afinar más la fuente probable de la pieza de don Pedro. Como se verá a continuación, de los tres santorales castellanos basados en la obra de Surio, el Flos sanctorum de Villegas es el que registra más coincidencias textuales con Los dos amantes del cielo; el de Ribadeneyra, el que menos.

En la comedia calderoniana, Claudio (sobrino de Polemio y primo-amigo del protagonista) recomienda a su tío que case a Crisanto 
para que, dedicado al cuidado de su esposa, se olvide de su fe. Esta información — referida a un pariente o amigo indeterminado en el texto de Surio, Villegas y Sanctoro- se omite en el florilegio de Ribadeneyra.

SURIO «Quidam igitur patri eius hoc consilium dedit: Si filium, inquiens, cupis ab hoc proposito dimovere, cura potius ut in deliciis \& voluptatibus versetur: eique pulcherrimam aliquam ac prudentem puellam uxorem adiunge: ut dum se maritum esse intellexerit, Christianum esse obliviscatun (p. 949)

VILlEgas «y como se divulgase entre los parientes y amigos [la conversión de Crisanto y su posterior prisión por ello], uno dellos habló a Polemio y díjole: Si deseas apartar a tu hijo de su propósito, procura regalarle y que se entretenga en deleites y pasatiempos carnales. Búscale una doncella prudente y hermosa con quien se case, y desta manera el cuidado de que tiene mujer, le hará que se olvide de que es cristiano» (p. 499a)

SAnctoro «Como esto se divulgó, habló a Polemio un su amigo, y díjole: Si deseas apartar a tu hijo deste propósito, no le dés tormentos sino mételo en deleites y regalos, y ajúntalo a una hermosísima y prudente mujer, para que entendiendo que es su marido, se olvide de ser cristiano» (p. 252r)

RibADENEYRA «Pareció al padre que era más a propósito buscar una doncella hermosa, graciosa, sabia y prudente, y casarla con su hijo, y hacerla heredera de su hacienda, para que acabase con Crisanto, como mujer legítima, lo que las criadas no habían podido acabar» (pp. 787b-788a)

Calderón «[Claudio] Aunque es, señor [en referencia a su tío Polemio], osadía / que yo a tus canas me atreva / a dar consejo, tal vez / joven se vio la prudencia» (p. 277); «Y si quieres, finalmente, / que de todas sus tristezas / se olvide y que sólo acuda / a una acción y ésa perfeta, / dale estado [...]" (p. 278); «Elija él; que sea su gusto. / Si él se casa, aunque pretenda / divertirse, no podrá / después; porque es cosa cierta / que un marido enamorado / de nada, señor, se acuerda» (p. 279)

En la leyenda son diversos los argumentos esgrimidos por Crisanto para cristianizar a Daría. Nuestro texto dramático comparte dos con los relatos transmitidos por Surio, Villegas y Sanctoro: la negación de 
la correspondencia de los dioses paganos con elementos de la naturaleza y el carácter vicioso, cruel y homicida de esas divinidades. Ribadeneyra suprimió ambos argumentos por la abbreviatio que operó en el pasaje.

Surio a) «Nam deorum nomina allegorice interpretantes, Saturnum dicunt esse tempus, Iovem caloris intensionem, Iunonem aerem appellant, Venerem ignem, Neptunum mare, Cererem terram: idemque faciunt in reliquis diis» (pp. 951-952)

b) «Quid igitur habet falcifer Saturnus probitatis, qui proprios filios vixdum in lucem editos sustulit, immo vero devoravit, ut ipsius cultores conscripsere? Aut quid in ipso Iove laudandum putas, qui quot dies vixit, tot flagitia, tot adulteria, tot homicidia perpetravit?» (p. 951)

Villegas a) «Dicen que Saturno significa el tiempo; Júpiter, el calor; Juno, el aire;Venus, el fuego; Neptuno, el agua; Ceres, la tierra; y así los demás» (p. 500b)

b) «¿Pues qué virtud y santidad hallarás tú en Saturno, que a sus proprios hijos dio la muerte siendo pequeños, y comía sus carnes después de haberlos muerto? Y en Júpiter, ¿qué ves tú para que merezca ser adorado, pues tantos cuantos días vivió, tantos adulterios, homicidios y otros hechos facinorosos cometió?» (p. 500b)

SANCTORO a) «interpretando alegóricamente los nombres de los dioses, dicen que Saturno es el tiempo; Júpiter, la intención del calor; Juno, el aire;Venus, el fuego; Neptuno, el mar; Ceres, la tierra; y lo mesmo dicen de los demás dioses» (p. 253r)

b) «¿Qué bondad o santidad tiene Saturno, que mató a sus hijos aun no bien nacidos y se los tragó, como lo escriben los mesmos que lo veneran? ¿En qué se debe loar Júpiter, pues perpetró tantas bellaquerías y adulterios y homicidios en todos los días que vivió?» (p. 252v)

Ribadeneyra «[Mas el Señor] le dio [a Crisanto] tal gracia del cielo y tan buenas y eficaces razones, hablando con Daría, que ella cayó en el lazo que armaba a Crisanto y, favorecida de Dios, se rindió y dijo que sería cristiana» (p. 788a) 
Calderón a) «[Daría] Pues, jJúpiter no hizo el cielo, / donde reside tonante? / [CRisanto] No [...] / [Daría] ¿Ceres no es la tierra? / [CRISAnto] No [...] / [DARÍA] ¿Saturno el tiempo no es? / [Crisanto] No lo es [...] / [Daría] ¿No es Venus el aire? / [Crisanto] Menos [...] / [Daría] ¿No es Neptuno el mar? / [Crisanto] Tampoco [...] / [Daría] ¿No es Marte el fuego? / [CRisanto] No [...] / [DARÍA] ¿El sol no es Apolo? / [Crisanto] No [...] / [Daría] ¿Diana la luna? / [Crisanto] Es dislate [...]» (pp. 311-312)

b) «[CRISANTO] ¿Cómo pudieran ser dioses / dioses que adulterios hacen, / homicidios, hurtos, muertes / y otras mil atrocidades / si el decir dios y delito / implica contrariedades?» (p. 312)

Demostrado, pues, que Calderón no pudo basarse solo en la lectura del Flos sanctorum de Ribadeneyra para escribir Los dos amantes del cielo, resta ahora evidenciar la mayor dependencia textual de esa pieza con el santoral de Villegas, y no con el de Sanctoro.

Cuando Polemio descubre el nuevo credo de Crisanto, iracundo, determina encerrarlo y someterlo a unas duras condiciones de cautiverio. En las versiones de Surio, Sanctoro y Ribadeneyra únicamente se alude a una oscura prisión; en la de Villegas esa cárcel se ubica en la propia casa del mártir. Lo mismo sucede en la comedia de don Pedro, en la que Polemio declara su responsabilidad en ese encierro: «mandé / traerle a mi casa mesma» (p. 273).Además,Villegas, Ribadeneyra (que en este punto sigue al maestro toledano) y Calderón coinciden - frente a Surio y Sanctoro - en la expresión lingüística que da cuenta de la escasa comida que se facilitaba a Crisanto en su prisión: dar a comer por/a tasa.

Surio «Iratus igitur Polemius pater, eum in obscuro foedoque carcere includendum curavit, \& paucissimo cibo vesperi tantum nutriendum» (p. 949)

Villegas «Airose demasiadamente Polemio. Fue a su casa y puso a su hijo Crisanto en una escura prisión; mandó darle a comer a tasa» (p. 499a)

SAnCtoro «Enojado con esto Polemio, mandó meter a Crisanto en una escura y sucia cárcel y que le diesen muy poco a comer» (p. 252r) 
Ribadeneyra «[Polemio] se ensañó fuertemente contra su hijo y le puso en una escura prisión, mandándole dar de comer por tasa» (p. 787b)

Calderón «[Polemio] Trújele preso, en efeto; / y haciendo misterio que era / justo que aquella prisión / en Roma no se supiera / por los cómplices, mandé / traerle a mi casa mesma» (p. 273); «Cerré ventanas y puertas, / cargándole de prisiones, / de grillos y de cadenas, / dándole a comer por tasa» (p. 275)

Por último, los relatos de Surio, Sanctoro y Ribadeneyra no especifican el número de criadas que Polemio dispone para seducir a su hijo y hacerle olvidar su fe. En cambio, Villegas y Calderón especifican su cantidad: dos; innominadas en el texto del primero, llamadas Nísida y Cintia en el del segundo.

SURIO «e numeroque suarum ancillarum formosissimas deligit, ornatasque» (p. 949)

Villegas «Mandó también [Polemio] a dos esclavas suyas, doncellas hermosas, que vestidas y aderezadas se entrasen con él» (pp. $499 a-499 b)$

SAnCtoro «y [Polemio mandó] que escogiesen las más hermosas de sus doncellas, y muy bien aderezadas las encerrasen con él» (p. 252r)

Ribadeneyra «[Polemio] tomó otro camino de blanduras y regalos, y por medio de unas mujeres hermosas, criadas suyas, pretendió pervertirle y solicitarle a mal» (p. 787b)

Calderón «[Crisanto] ¿Qué es lo que a las dos [Nísida y Cintia] sucede / que han perdido el juicio entrambas?» (p. 302, en referencia al prodigio que libra al protagonista de su tentación; ver pp. 298-302)

En definitiva, a falta de descubrir — si lo hubo - algún testimonio en castellano que transmitiese de forma exenta la pasión de Crisanto y Daría, el Flos sanctorum de Villegas parece la fuente primordial de Los dos amantes del cielo. Ello no permite descartar la consulta, por parte de Calderón, de otros santorales aparentemente más alejados, como los de Surio, Sanctoro o Ribadeneyra e, incluso, de algunos más. Como ya indicó Natalia Fernández en el caso de las fuentes de El mágico prodigioso, 
«Lo más plausible es que el dramaturgo no solo conociese otras versiones castellanas de la historia [distintas de las de Villegas], sino incluso el amplio sustrato legendario que se fijó en los testimonios primigenios» ${ }^{20}$.

\section{Los PRINCIPALES CAMBIOS INTRODUCIDOS POR CALDERÓN EN LA LEYENDA}

La transformación del relato hagiográfico en texto dramático conllevó algunos cambios en el elenco de las dramatis personae, la eliminación de varios episodios, la modificación de otros y no pocas novedades argumentales. Es decir, en Los dos amantes del cielo, de manera similar a lo que sucede en la comedia Judas Macabeo, «Las libertades que se toma don Pedro con respecto a su fuente son muchas» ${ }^{21}$.

Por lo que se refiere a los personajes, Calderón —además de introducir la figura del gracioso, Escarpín- aumentó la importancia de algunos de ellos, no solo por la mayor extensión de su papel, sino también por la duplicación de sus funciones. Así sucede con Polemio, quien a su faceta como padre de Crisanto suma la de perseguidor y verdugo de los mártires. A él se deben el encarcelamiento de su hijo (en dos ocasiones), la decapitación de un esclavo inocente y de Carpoforo, la decisión de enviar a Daría a un burdel y el enterramiento final ("Coged a los dos y en esa / cueva oscura, cuyo centro / es un abismo, arrojaldos», p. 334). Como señaló Cruickshank, «Polemio es un padre romano característicamente inflexible que preferiría ver a su hijo muerto antes que presenciar que ofende a los dioses de Roma» ${ }^{22}$. La extraordinaria violencia del personaje explica la supresión de las autoridades que atormentaban a los protagonistas en la leyenda (el tribuno Claudio y el prefecto Celerino) y la reducción del papel del emperador Numeriano (al que solo se cita en el texto dramático). Otros personajes que también están más desarrollados en la pieza teatral son: Carpoforo, el pariente que aconseja a Polemio (su sobrino Claudio) y las jóvenes que intentan seducir a Crisanto (Nísida y Cintia). La labor adoctrinadora de Carpoforo se distribuye a lo largo de las tres jornadas, registrándose en la última su martirio, ausente de la leyenda. Tampoco figuraba en esta su rol fingido como «un gran médico» (p. 293) que intentará curar con fe el 'mal' del alma de Crisanto. En lo que atañe a Claudio, su función en la comedia

\footnotetext{
${ }^{20}$ Fernández Rodríguez, 2009a, p. 19.

${ }^{21}$ Rodríguez-Gallego, 2012, p. 17.

${ }^{22}$ Cruickshank, 2011, p. 334.
} 
es doble: como familiar, asesora a su tío y procura distraer a su primo (propiciando su encuentro con Daría); como galán, aspira — solo inicialmente - al amor de Cintia. El papel de esta y de Nísida, como sacerdotisas de Diana y como tentadoras de Crisanto, fue muy amplificado por don Pedro. Junto con Daría protagonizan una sensual escena (pp. 247-255) que presenta sus respectivos encantos femeninos en medio de una bella floresta: la dulce voz de Nísida, el agudo ingenio de Cintia y la hermosura física de Daría. En su intento de enamorar a Crisanto se detallan de forma sensorial esas 'armas' de seducción que arrebatan en un primer momento el alma del joven ${ }^{23}$ :

$\begin{array}{ll}\text { Crisanto } & {[\text { A Nísida] iQué dulce voz! ¡Qué bien suena! }} \\ & \text { El alma arrebata el canto. } \\ \text { ¿Quién de tan suave encanto } \\ \text { se libró? Dulce sirena, } \\ \text { déjame; que a ser despojos } \\ \text { el alma tu voz provoca. (p. 299) } \\ \text { [A Cintia] No es música solamente } \\ \text { la de la voz que entonada } \\ \text { se escucha; música es } \\ \text { cuanto hace consonancia. } \\ \text { [...] tú, con números medidos, } \\ \text { suspensa has dejado el alma. } \\ \text { ¡Qué sutilmente discurres! (p. 301) }\end{array}$

En cuanto al ya citado Escarpín, a su tópica caracterización como gracioso añade su faceta como vulgar pretendiente de Daría, interesado exclusivamente en el acceso carnal a la doncella. De ahí que asuma el papel del mozo anónimo que en la leyenda acudía al prostíbulo a comprar el forzamiento de la virgen:

EsCARPín $\quad[\ldots]$ pues que por su justo precio este humano bodegón

${ }^{23}$ Esta situación dramática es frecuente en las comedias hagiográficas. Un ejemplo se halla en El más ilustre francés, San Bernardo, de Moreto, cuyo arranque en la etapa juvenil del santo se debe — según Oteiza, 2005, p. 937- a que «este periodo, según cuenta su hagiografia, está lleno de tentaciones de la carne, lo que permite a Moreto una cómoda inserción de materiales profanos y de lo cómico, "exigidos" y aplaudidos por el público». 
tiene ya su arancel para

cualquier humano favor,

dame, Daría, los brazos. (p. 327)

Por lo que respecta a la supresión de pasajes del relato hagiográfico, Calderón prescindió - como era de esperar- de algunos episodios digresivos (como el de la tentación de José por la mujer de Putifar) o secundarios (como el de la conversión y martirio del tribuno Claudio). Asimismo, omitió numerosos tormentos de los que se libró milagrosamente Crisanto, pues prefirió concentrar su atención en la tentación carnal a que este fue sometido. Esta trama secundaria amorosa se analiza más tarde, cuando se detallen los componentes profanos que don Pedro potenció en su comedia.

Los principales cambios realizados en la historia de Crisanto y Daría para adecuarla a las convenciones de una comedia de santos supusieron un mayor desarrollo de los tres elementos básicos de este subgénero dramático: el religioso, el espectacular y, sobre todo, el profano ${ }^{24}$.

1. En lo relativo a la faceta religiosa, Calderón incrementó la carga teológica de su texto con un tratamiento explícito de ciertos contenidos doctrinales. Al inicio de la obra se citan los pasajes bíblicos (Jn 1, $1-2,14)$ que crean confusión en la mente reflexiva de Crisanto: «En el principio era el Verbo» (p. 235), «el Verbo estaba / en Dios, que era el mismo Verbo; / y este era en el principio» (p. 236) y «El Verbo fue hecho carne» (p. 237). Durante el primer encuentro del joven pagano con Carpoforo se pone en boca del segundo una explicación vulgarizada de la naturaleza humana y trina del Dios cristiano:

Carpoforo Es Dios porque es increado, sin principio y fin; es Verbo porque es también engendrado del Padre, de quien procede luego el Espíritu Santo, siendo un Dios y tres personas. $[\ldots]$

Fe católica es que una trinidad siempre creamos, ni confundiendo personas, ni sustancias separando.

${ }^{24}$ Ver, sobre ello, Dassbach, 1997, y Martínez Berbel, 2008, pp. 40-42. 
Del Padre, una es la persona; otra, la del Hijo amado; y otra persona también la del Espíritu Santo. (p. 263)

En el proceso de conversión de Daría a cargo de Crisanto es este quien asume la predicación de esos mismos principios católicos (pp. 318-319), inexistentes en el relato hagiográfico primigenio.

El papel de Carpoforo como falso doctor que procura la salud espiritual de Crisanto es — ya se ha dicho- invención de don Pedro. La función del personaje consiste ahora en prevenir al joven de la posterior tentación mujeril y aconsejarle fortaleza para poder resistirla:

$\begin{array}{ll}\text { Carpoforo } & \text { Y solo lo que te advierto } \\ & \text { es que te aguarda y espera } \\ & \text { la lid más sangrienta y fiera } \\ & \text { de los hombres; pues es cierto } \\ & \text { que, de mujeres buscado, } \\ & \text { de deseos combatido, } \\ & \text { de lascivias oprimido } \\ & \text { y de deleites cercado, } \\ & \text { te has desde este día ver. }\end{array}$

No te dejes vencer de ellas. (p. 295)

También ayuda al protagonista a no sucumbir a su pasión amorosa por Daría, recriminándole su rendición momentánea «al agradable / hechizo de una hermosura» (p. 315). El martirio de Carpoforo a manos de Polemio, novedoso igualmente en la pieza calderoniana, sirve de acicate definitivo para que Crisanto consolide su fe y acepte el sufrimiento y la muerte que por ella le aguardan: «Si este [Carpoforo] a su maestro [Jesucristo] imitó, / mátame; que es importuno / error que él aprenda de uno / y de dos no aprenda yo» (p. 321).

Por otra parte, Calderón aumentó considerablemente la tensión dramática de la trama religiosa. Frente a la rápida y firme conversión de Crisanto en la leyenda, en la comedia su cristianización es más gradual y titubeante, siempre expuesta a su rendición ante los encantos de la hermosura — «[Crisanto a Carpoforo] Pues, ¿quién de mujeres bellas / se ha podido defender?» (p. 295) — o de la pasión — "[Crisanto a Daría] Pues ¿cómo sin ti podré / vivir yo, si son imanes / tus ojos [...]» (p. 314)—. Como bien señaló Dassbach, «Las tentaciones [...] no se pre- 
sentan como una mera convención para reforzar la virtud del santo, sino que se utilizan para intensificar el conflicto y crear verdadera tensión dramática» ${ }^{25}$. Solo en la última jornada, tras la degollación de su maestro, Crisanto proclama abiertamente la solidez de su conversión, su casto amor por Daría y su disposición al sacrificio. Lo mismo sucede con la conversión de Daría a cargo de Crisanto. A la lucha dialéctica entre ambos, don Pedro añadió una lid amorosa con alta tensión, ausente de la leyenda. En esa batalla el joven admite que «Rendirase el corazón» (p. 304), aunque no su entendimiento; y la doncella, que su «tirana pasión» la arrastra contra su voluntad a volver a ver a Crisanto (p. 317). Asimismo, la doble interrupción de la evangelización de Daría, al final de la segunda jornada y — ya en la tercera - con la huida de aquella por temor a ser convencida por Crisanto, incrementa el suspense en esta trama.

2. En lo tocante al elemento espectacular relacionado con la trama religiosa, Calderón compensó la eliminación de muchos milagros de la leyenda (por los que Crisanto se libraba de sucesivas torturas) con la invención de variadas manifestaciones de lo sobrenatural: profecías, voces y músicas celestiales, intervenciones angélicas, otros milagros y hasta un terremoto en medio de un eclipse solar. Como resulta obvio, este «espectáculo maravilloso, que forma parte de la codificación del género, provee una riqueza escenográfica peculiar» ${ }^{26}$.

En el cuadro inicial de la primera jornada se escuchan dos voces del más allá que defienden, contraponiéndolas, las creencias paganas y las cristianas: "[Voz 1 $\left.{ }^{a}\right]$ Solo a Júpiter adora», «[Voz 2a $]$ Adora a Dios» (p. 238). Se trata de una representación simbólica de la batalla interior del protagonista, escindido por sus dudas religiosas. Más tarde, tras el encuentro de Crisanto con Carpoforo y la posterior detención de ambos, se produce una repentina aparición angélica («Baja un ángel en una tramoya», p. 265 [en acotación]) que se lleva por el aire —en un desplazamiento aéreo digno de admiratio - al maestro cristiano. De este modo se retrasa el martirio de Carpoforo y este puede seguir ayudando al joven en la consolidación de su fe:

\footnotetext{
${ }^{25}$ Dassbach, 1997, p. 44.

${ }^{26}$ Teulade, 2008, p. 87.
} 
Ángel Carpoforo, aún no ha llegado [el día de tu deseado martirio]. Porque quiero acrisolar la constancia de Crisanto, no le guardo; pero a ti, desta manera te guardo.

Llévasele (p. 265)

En la segunda jornada, a través de una profecía se revela a Daría su glorioso final (pp. 282-283). Una caída accidental junto a la boca de la cueva donde hallará la muerte propicia la anticipación de su martirio. Se lo comunica una música misteriosa cantada por unas voces acompañadas de un instrumento de "dulcísima armonía» (p. 282). El diálogo que la virgen entabla con esas voces no resuelve, sin embargo, su incertidumbre: Daría desconoce todavía la identidad de quien ordena que muera sepultada allí, de quien - Jesucristo- «ya por ti [por ella] / enamorado murió» (p. 283). Solo cuando la doncella se enfrente al suplicio final comprenderá el mensaje y asentirá su verdad: «el gran anuncio de que / sería feliz [el día de su muerte], es cierto» (p. 335).Y la misma música vuelve a salir de la gruta después del fallecimiento de los santos.

En la escena central de la tentación de Crisanto, la ayuda divina se manifiesta de manera milagrosa. A la petición de auxilio del joven, Dios responde suspendiendo las facultades sensoriales de Nísida («Torpes las manos y heladas, / [...] / y a la voz, aliento falta", p. 302) y las intelectivas de Cintia («la razón equivocada, / la memoria confundida», p. 302), convirtiendo a ambas en estatuas vivas sin voz, vista ni juicio.

En la última jornada se ofrece el espectáculo truculento - tan propio de lo hagiográfico como del gusto popular- de la cabeza cortada de Carpoforo: «descubren a Carpoforo en una mesa degollado, cubierta la cara con un tafetán» (p. 319, en acotación). Al impacto de su visión se añade la admiración por el milagro que protagoniza: aun separada del tronco, habla (p. 320). Lo que para Polemio es un encanto mágico, para su hijo es un prodigio divino:

Crisanto Señor, a prodigios tantos no niegues la admiración; ni los que milagros son encantos llames, [...] (p. 320)

Al final de la comedia, como era previsible, tras el martirio de la pareja se concentran varios recursos escénicos «para que la santidad sea 
reconocida y admirada por los espectadores internos $»^{27}$. Como ya indicó Wardropper, "Among other miraculous signs of divine displeasure at this act [como un eclipse de sol o la aparición de viento y de cometas por el cielo] is a seismic movement that causes a boulder to roll down a mountain to seal the cave forever» ${ }^{28}$. La apoteosis se cierra cuando, en medio de la música celestial ya comentada, «aparece un ángel en una apariencia» ( $\mathrm{p}$. 335, en acotación) y se erige en portavoz de Dios: el peñasco que con el terremoto ha sellado la cueva guardará eternamente las cenizas de los santos, al mismo tiempo que servirá de losa de su monumento con la oportuna inscripción funeraria. El espectáculo — visual, sonoro y literario- es total.

En lo concerniente a la espectacularidad vinculada a la trama amorosa, también Calderón recurrió a elementos musicales y visuales inexistentes en el relato hagiográfico original. La presentación de las jóvenes sacerdotisas de Diana se localiza en unas «selvas bellas» que «son verdes cielos de flores, / son azul campo de estrellas», un auténtico "dosel de la primavera / matizado de colores» (p. 247). Este espacio dramático no debía limitarse a una mera descriptio verbal puesta en boca de los personajes, sino que probablemente se representaba sobre las tablas de manera más o menos colorista y compleja. Así lo dan a entender las referencias a la fuente en que Daría contempla su belleza ( me he de mirar a esta fuente», p. 253) y a la verdura del ambiente («esta verde estancia / donde agora hemos venido", p. 253). Desde el punto de vista auditivo, se escuchan las canciones "Ruiseñor que volando vas» (en dos ocasiones, pp. 248 y 253) y "iQué alegre y desvanecido / cantas, dulce ruiseñor» (p. 249) interpretadas por Nísida, quien se acompaña de un $\operatorname{arpa}^{29}$. El carácter atractivo de esta música es resaltado en el propio texto:

Cintia La soledad discurriendo, venía unos versos leyendo cuando la dulzura oí de tu voz; y ella el imán

${ }^{27}$ Teulade, 2008, p. 92.

${ }^{28}$ Wardropper, 1989, pp. 156-157.

29 Cruickshank, 2011, p. 333, recuerda que «La canción interpretada por Nísida, "Ruiseñor que volando vas" (I, 776a), tiene música, conservada hasta hoy, de Juan Vado, de quien se sabe que fue violinista de la Capilla Real en 1635, pero esa misma canción se encuentra en el acto de La fingida Arcadia escrito por Calderón, y en Fieras afemina Amor (1671)». 
de mis acciones ha sido;

ella tras ti me ha traído. (p. 248)

Precisamente la naturaleza cautivadora de esa voz llevará a Crisanto a identificarla con una sirena (p. 299) ${ }^{30}$. Tan arrebatador le resulta su canto que ignora, sin ayuda de Dios, «cómo hacer / resistencias al oír!» (p. 299). Como apuntó Natalia Fernández, en las comedias hagiográficas a menudo la música «se convierte en un estímulo hedonista al servicio del demonio» ${ }^{31}$.

3. La importancia fundamental que don Pedro concedió al elemento profano se manifiesta desde el propio título de la comedia, Los dos amantes del cielo. La omisión de los nombres de los santos contrasta con su alusión a través del término amantes, y esta referencia profana antecede a la religiosa del cielo. Se diría que Calderón procuraba atraer el interés del público más por la historia de amor de los protagonistas que por la dramatización de su martirio. $\mathrm{O}$, dicho de otro modo, Crisanto y Daría se presentan antes como enamorados que como santos. De hecho, así sucede en la pieza teatral hasta bien entrada la tercera jornada. No ocurre lo mismo, en cambio, en la leyenda, donde nunca existe realmente tensión amorosa entre ellos.

La trama secundaria amorosa está claramente integrada en la religiosa, pues ilustra la renuncia de Crisanto y Daría al amor humano y la superación de los obstáculos que entorpecían su santidad. El tratamiento de esos episodios es, sin embargo, considerablemente distinto en el relato hagiográfico y en la comedia.

En el texto dramático el encuentro de Crisanto y Daría es anterior al de Crisanto y Carpoforo. Es decir, previamente a la cristianización del protagonista, este asume antes el papel de galán que el de convertido. La simple contemplación de la hermosura de Daría rinde su corazón («todo es Babilonia el pecho, / todo es Troya el corazón», pp. 255-256) y lo inicita a la conquista amorosa («tan bella estáis / que, quienquiera que seáis, / he de hablaros con amor», p. 257). La dificultad de la conversión de Crisanto en la comedia es, pues, doble: no solo deberá superar el episodio de la tentación, sino también su sincera pasión por Daría.

${ }^{30}$ A este respecto, ya había notado Arellano, 2000, p. 237, que «Mezcla de humano y animal, monstruos mitológicos y fabulosos, son las sirenas, que representan a la tentación en El José de las mujeres (vv. 1391-92), o en Los dos amantes del cielo (193)».

${ }^{31}$ Fernández Rodríguez, 2009b, p. 179. 
La función demoníaca de arrastrar al joven a una lujuria pagana no es asumida - como en la leyenda - por criadas de Polemio. En la obra calderoniana son tres sacerdotisas de Diana (Nísida y Cintia primero, y Daría después) las que aceptan voluntariamente el reto de enamorarlo. La tentación se ha convertido, por obra de don Pedro, en un "certamen entre mujeres» (p. 287), en una pugna de encantos femeninos para lograr vencer la resistencia de Crisanto. Las dos acometidas amorosas están más desarrolladas en el texto dramático, pero especialmente la referida a Daría. Durante el proceso de conversión de esta, el apasionamiento de Crisanto parece más fuerte que su fe: según Polemio, su hermosura «tan rendido le trae / que en el instante se muere / que de aquí falta un instante» (p. 306). Lo mismo siente Daría, dominada por el ardor amoroso: "hablarle / ha despertado en mi pecho / vivo fuego que me abrase» (p. 310). Solo tras el martirio de Carpoforo se esfumará la constante tensión amorosa entre la pareja protagonista, entre cristianismo y paganismo, bien y mal, autodominio y pasión.

Además, Calderón extendió la trama amorosa a dos parejas más: Claudio-Cintia y Escarpín-Daría, ambas de imposible éxito. En la primera, por el desengaño de Claudio al saber que Cintia fue a ver a Crisanto para conquistarlo (p. 308); en la segunda, por la condición vulgar y paródica del amor del gracioso, del que se trata un poco más adelante.

Por otra parte, frente a su limitado desarrollo en la leyenda, en la comedia se aborda extensamente otro motivo temático característico de don Pedro: el conflicto paterno-filial. Este asunto refuerza la temática religiosa de la pieza, pues complica la conversión de Crisanto y exalta su valor ante el sufrimiento y la muerte que su padre, Polemio, le procura. La violencia paterna se presenta en el texto dramático de modo paulatino. El apresamiento inicial del protagonista junto con Carpoforo sume a Polemio en un angustioso debate: dos sentimientos contrarios batallan en su interior: el amor por su hijo y la lealtad con su emperador, perseguidor de los cristianos:

Polemio $[\ldots]$ ¿Qué he de hacer en tantas dudas?
Si digo quién es, infamo
con su culpa mi nobleza;
y mi lealtad, si lo callo,
pues, en solo hallarle aquí,
quiebro del césar el bando.




\section{¿Castigarele? Es mi hijo. \\ ¿Librarele? Es mi contrario. \\ Pues entre estos dos estremos, haya un medio. No le hallo, que como juez le aborrezco y como padre le amo). (p. 268)}

La imponente crueldad de Polemio se manifestará de forma progresiva en el asesinato de un esclavo inocente, en el inhumano rigor de la prisión de su hijo, en la muerte infligida a Carpoforo, en las penas decretadas a la pareja protagonista (para cada uno, la «más contraria a su deseo, / por hacer más importuno / su dolor», p. 323) y en el martirio final (en el que participa activamente: «Y yo he de ser el primero / que los dé muerte», p. 334).

Ante el espectáculo horrendo de la cabeza decapitada de Carpoforo, Crisanto renuncia a su padre terrenal, reconociéndose hijo solamente del padre que muere por él (Jesucristo, Carpoforo), no del que por él mata:

$\begin{array}{ll}\text { Crisanto } & \text { Padre, aunque muerte te pido... } \\ \text { Polemio } & \text { Ese nombre no me des. } \\ \text { Crisanto } & \text {... no hablaba contigo; pues, } \\ & \text { aunque tú a mi vida diste } \\ & \text { el ser, de padre perdiste } \\ & \text { el dulce nombre después } \\ & \text { que otro con más alta palma } \\ & \text { el ser del alma me dio; } \\ & {[\ldots] \text { porque si tu mano ingrata }} \\ & \text { vierte el humor que él [Carpoforo] desata, } \\ & \text { más de padre el nombre adquiera } \\ & \text { el padre que por mí muera } \\ & \text { que el padre que por mí mata (p. } 321)\end{array}$

Por último, trataré brevemente de la comicidad introducida por don Pedro en la historia de Crisanto y Daría. El gracioso Escarpín es quien cumple en exclusiva esa función en la comedia. Usa para ello recursos cómicos propios del conceptismo jocoso, entre otros: anacronismos ridículos que suponen un guiño al espectador ("[referido a Polemio] El primer padre alcahuete / es que yo en mi vida vi», p. 296; «va otro [cuento]. 
Un fraile... No, no es bueno, / porque en Roma no había frailes», p. 309), nueve cuentos que ejemplifican una supuesta lectio grave ("cuatro en el acto I, otros tantos en el II y solo uno en el último») $)^{32}$, alguna frase proverbial con intención chistosa («Frutas y mujeres, / cuando abaratarlas vieres, / es cuando saben más bien», p. 326) y variados juegos de palabras («[no sé] si es Daría, diese u diera; / pero sé que tomaría, / tomara y tomase de ella [...]», p. 270; «vuestros no sé qués y sí sé qués», p. 287; «¿quién un cabe no tiró, / puesto de paleta el cabe?», p. 309).

Pero Escarpín ofrece, además, un claro paralelo contrastivo y paródico con Crisanto. Como ya advirtió Natalia Fernández en El mágico prodigioso, las intervenciones del gracioso "constituyen una especie de reflejo invertido de las acciones principales» ${ }^{33}$.Y ello en una doble vertiente: amorosa y religiosa. Frente al amor puro, casto, de Crisanto por Daría, Escarpín siente un deseo carnal, bajo, por ella. Tan atrevidas son sus palabras en el prostíbulo adonde se han llevado a la virgen, que «alguien, probablemente un censor, se vio en la necesidad de tachar muchos de sus versos en la versión manuscrita [de la comedia]» ${ }^{34}$. Y en contraposición al heroísmo cristiano de su amo, que pide y acepta valientemente el martirio, da muestras evidentes de su cobardía, tanto fisica (durante el ataque del león en el burdel: «Cuanto ha que gallina soy, / lindos miedos he tenido", p. 330) como espiritual (por temor a posibles represalias no abraza con convencimiento ninguna religión: «[es bien] estarme como me estoy, / ni cristiano ni gentil, / sino un medio entre los dos», p. 330 $)^{35}$.

\section{FINAL}

En conclusión, Calderón modificó sustancialmente el relato hagiográfico de Crisanto y Daría que leyó - entre otros legendarios- en el Flos sanctorum de Alonso de Villegas, la fuente más probable de Los dos amantes del cielo. Don Pedro desarrolló más algunos personajes de la leyenda (Carpoforo, el familiar que aconseja a Polemio y las jóvenes seductoras de Crisanto), suprimió varios pasajes secundarios y potenció los componentes religioso, espectacular y, sobre todo, profano de la

32 Barone, 2012, p. 93. Esta estudiosa analiza dos de esos cuentos (pp. 93-95).

${ }^{33}$ Fernández Rodríguez, 2009a, p. 39.

${ }^{34}$ Ruano de la Haza, 2010, p. XviII.

${ }^{35}$ Para Barone, 2012, p. 96, Escarpín «tiende a la neutralidad siguiendo el principio de no participación en la acción que distingue normalmente la conducta del gracioso». 
historia. Frente al texto primigenio, en la comedia se explicitan algunos contenidos doctrinales, se despliegan muchos y variados recursos escenográficos (para dramatizar tanto lo sobrenatural como lo sensual), se intensifican el conflicto paterno-filial y la trama amorosa entre Crisanto y Daría, y se introduce la 'exigida' comicidad mediante la figura del gracioso. 


\section{BiBLIOGRAFÍA}

Acta Sanctorum, Octobris, ed. Josepho Van Hecke, t. 11, Benjamino Bossue, Eduardo Carpentier,Victore et Remigio de Buck, Bruxellis, Typis Henrici Goemaere, 1864.

ArAgüÉs Aldaz, José, «El santoral castellano en los siglos XVI y XVII. Un itinerario hagiográfico», Analecta Bollandiana, 118, 2000, pp. 329-386.

AragüÉs Aldaz, José, «Tendencias y realizaciones en el campo de la hagiografia en España (con algunos datos para el estudio de los legendarios hispánicos)», en Memoria Ecclesiae XXIV. Hagiografía y archivos de la Iglesia santoral hispano-mozárabe en las diócesis de España, ed. Agustín Hevia Ballina, Oviedo, Asociación de Archiveros de la Iglesia en España, 2004, pp. 441-560.

AragüÉs Aldaz, José, «Para el estudio del Flos sanctorum renacentista (I). La conformación de un género», en Homenaje a Henri Guerreiro. La hagiografía entre historia y literatura en la España de la Edad Media y del Siglo de Oro, ed. Marc Vitse, Madrid, Iberoamericana, 2005, pp. 97-147.

ArAgüÉs AldAz, José, «Los Flores sanctorum medievales y renacentistas. Brevísimo panorama crítico», en Literatura medieval y renacentista en España: líneas y pautas, ed. Natalia Fernández Rodríguez y María Fernández Ferreiro, Salamanca, Sociedad de Estudios Medievales y Renacentistas, 2012, pp. 349-361.

ArAgüés Aldaz, José, «La difusa autoría del Flos sanctorum. Silencios, presencias, imposturas», en El autor oculto en la literatura española. Siglos XIV a XVIII, ed. Maud Le Guellec, Madrid, Collection de la Casa de Velázquez, 140, 2014, pp. 21-40.

Arellano, Ignacio, "Elementos emblemáticos en las comedias religiosas de Calderón», en Calderón, una lectura desde el siglo XXI, ed. María G. Gómez y Patiño, Alicante, Instituto Alicantino Juan Gil-Albert, 2000, pp. 221-247.

Barone, Lavinia, El gracioso en los dramas de Calderón, New York, IDEA, 2012.

Bibliotheca Hagiographica Latina Antiquae et Mediae Aetatis, Bruxelles, Société des Bollandistes, 1949, 2 vols.

Calderón de la Barca, Pedro, Los dos amantes del cielo, en Comedias, V, Verdadera quinta parte de comedias, ed. José María Ruano de la Haza, Madrid, Fundación José Antonio de Castro, 2010, pp. 233-336.

Cruickshank, Don W., Calderón de la Barca. Su carrera secular, trad. José Luis Gil Aristu, Madrid, Gredos, 2011.

Dassbach, Elma, La comedia hagiográfica del Siglo de Oro español. Lope de Vega, Tirso de Molina y Calderón de la Barca, New York, Peter Lang, 1997.

Delehaye, Hippolyte, The Legends of the Saints, trad. Donald Attwater, Dublin, Four Courts Press, 1998 [1955]. 
FERnÁndez Rodríguez, Natalia, «De la leyenda ejemplar a la indagación filosófica: Calderón y El mágico prodigioso", en Pedro Calderón de la Barca, El mágico prodigioso, ed. Natalia Fernández, Barcelona, Crítica, 2009a, pp. 7-65.

FERnÁndez Rodríguez, Natalia, La pecadora penitente en la comedia del Siglo de Oro, Valladolid, Universidad de Valladolid, 2009b.

GonzÁlez Lopo, Domingo L., «Los nuevos modos de la hagiografía contrarreformista», en Memoria Ecclesiae XXIV. Hagiografía y archivos de la Iglesia santoral hispano-mozárabe en las diócesis de España, ed. Agustín Hevia Ballina, Oviedo, Asociación de Archiveros de la Iglesia en España, 2004, pp. 608-632.

Hilborn, Harry Warren, A Chronology of the Plays of D. Pedro Calderón de la Barca, Toronto, The University of Toronto Press, 1938.

Leyenda de los santos (que vulgarmente Flos Santorum llaman) [Sevilla, Juan de Varela, 1520-1521], ed. Félix Juan Cabasés, Madrid, Universidad Pontificia de Comillas/Institutum Historicum Societatis Iesu, 2007.

Lipomano, Luigi, De vitis sanctorum, pars prima, Lovanii, Martinum Verhasselt, 1571 (ejemplar de la Biblioteca de la Universidade de Santiago de Compostela [BUSC], signatura: 16211).

Lipomano, Luigi, Vitarum sanctorum priscorum patrum, Romae, ex Officina Salviana, t. 6, 1558 (BUSC, signatura: INC 968-6).

Maggioni, Giovanni Paolo, «Fonti citate», en Iacopo da Varazze, Legenda aurea, ed. Giovanni Paolo Maggioni, Firenze, Sismel/Edizioni del Galluzzo, 1998, pp. XXXVII-LXVI.

Martínez Berbel, Juan Antonio, «La comedia de santos entre la heterodoxia y la licitud», en La comedia de santos. Coloquio Internacional (Almagro, 1, 2 y 3 de diciembre de 2006), ed. Felipe B. Pedraza Jiménez y Almudena García González, Cuenca, Universidad de Castilla-La Mancha/Casa de Velázquez, 2008, pp. 39-52.

Martirologium secundum morem Romanae curie, [Parisis?], 1536 (BUSC, signatura: 7983).

Mauro, Rabano, Martyrologium, ed. John McCulloh, Turnholti, Typographi Editores Pontificii, 1979.

Menéndez Peláez, Jesús, «El teatro hagiográfico en el Siglo de Oro español: aproximación a una encuesta bibliográfica», en Memoria Ecclesiae XXIV. Hagiografía y archivos de la Iglesia santoral hispano-mozárabe en las diócesis de España, ed. Agustín Hevia Ballina, Oviedo, Asociación de Archiveros de la Iglesia en España, 2004, pp. 721-802.

Oteiza, Blanca, «San Bernardo: historia y poesía en Moreto y Bances Candamo (con Hoz y Mota)", en Homenaje a Henri Guerreiro. La hagiografía entre historia y literatura en la España de la Edad Media y del Siglo de Oro, ed. Marc Vitse, Madrid, Iberoamericana, 2005, pp. 931-949.

Ribadeneyra, Pedro de, Flos sanctorum, Madrid, Luis Sánchez, 1610 (BUSC, signatura: 11192). 
Rodríguez-Gallego, Fernando, «Introducción», en Pedro Calderón de la Barca, Judas Macabeo, ed. Fernando Rodríguez-Gallego, Madrid/Frankfurt, Iberoamericana/Vervuert, 2012, pp. 11-32.

RuANO DE la HazA, Jose María, «Introducción», en Calderón de la Barca, Pedro, Comedias, V, Verdadera quinta parte de comedias, Madrid, Fundación José Antonio de Castro, 2010, pp. IX-XLV.

Sanctoro, Juan Basilio, Segunda parte de la hagiografía y vidas de los santos del Nuevo Testamento, Bilbao, Mathias Mares, 1580 (BUSC, signatura: 22744).

Simón Díaz, José, «Hagiografías individuales publicadas en español de 1480 a 1700», Hispania sacra, 30, 1977, pp. 421-480.

Surio, Laurentio, De probatis sanctorum historiis, Coloniae Agrippinae, t. 5, Gervinum Calenium \& haeredes Quentelios, 1574 (BUSC, signatura: 8219).

Teulade, Anne, «Santidad y teatralidad: el santo como paradoja estética», en La comedia de santos. Coloquio Internacional (Almagro, 1, 2 y 3 de diciembre de 2006), ed. Felipe B. Pedraza Jiménez y Almudena García González, Cuenca, Universidad de Castilla-La Mancha/Casa de Velázquez, 2008, pp. 85-99.

Usuardo, Le Martyrologe d'Usuard, ed. Jacques Dubois, Bruxelles, Société des Bollandistes, 1965.

Vega, Pedro de la, Flos sanctorum: el más copioso que hasta agora ha sido impreso, Sevilla, Juan Gutiérrez, 1569 (BUSC, signatura: 24737).

Villegas, Alonso de, Flos sanctorum, Madrid, Bernardo de Villa-Diego, 1672 (BUSC, signatura: INC 174-3).

VorÁgine, Santiago de la [Iacopo da Varazze], Legenda aurea, ed. Giovanni Paolo Maggioni, Firenze, Sismel/Edizioni del Galluzzo, 1998, 2 vols.

Wardropper, Bruce W., «Time, Anachronism, and Eternity in Calderon's Martyr Play Los dos amantes del cielo», en Estudios sobre Calderón y el teatro de la Edad de Oro. Homenaje a Kurt y Roswitha Reichenberger, ed. Francisco Mundi Pedret, Barcelona, Promociones y Publicaciones Universitarias, 1989, pp. 155-163. 